\title{
Practical based approach to left main bifurcation stenting
}

\author{
Jung-Min Ahn, Pil Hyung Lee and Seung-Jung Park
}

\begin{abstract}
Despite the recent developments that have been made in the field of percutaneous left main (LM) intervention, the treatment of distal LM bifurcation remains challenging. The provisional one-stent approach for LM bifurcation has shown more favorable outcomes than the two-stent technique, making the former the preferred strategy in most types of LM bifurcation stenosis. However, elective two-stent techniques, none of which has been proven superior to the others, are still used in patients with severely diseased large side branches to avoid acute hemodynamic compromise. Selecting the proper bifurcation treatment strategy using meticulous intravascular ultrasound evaluation for side branch ostium is crucial for reducing the risk of side branch occlusion and for improving patient outcomes. In addition, unnecessary complex intervention can be avoided by measuring fractional flow reserve in angiographically isolated side branches. Most importantly, good long-term clinical outcomes are more related to the successful procedure itself than to the type of stenting technique, emphasizing the greater importance of optimizing the chosen technique than the choice of method.
\end{abstract}

Keywords: Left main coronary artery, Percutaneous coronary intervention, Bifurcation, Intravascular ultrasound, Fractional flow reserve

\section{Background}

Results of randomized trials and observational studies found that percutaneous coronary intervention $(\mathrm{PCI})$ is a potential alternative to bypass surgery for patients with unprotected left main (LM) coronary artery stenosis [1]. However, PCI for LM bifurcation is technically demanding and has been associated with high rates of adverse clinical events [2]. In addition, a lack of randomized clinical trials focusing on distal LM intervention has often led to uncertainties regarding the optimal stenting strategy. In general, based on non-randomized studies and extrapolations from the results of non-LM bifurcation trials, the provisional one-stent approach has been considered as a preferred strategy over the elective two-stent technique for patients with LM bifurcation disease. In practice, however, two-stent techniques are chosen more frequently for LM bifurcation than for non-LM lesions due to concerns regarding the ischemic myocardial volume, which would be jeopardized by adverse events [3]. This review therefore discusses the optimal methods of

\footnotetext{
* Correspondence: sjpark@amc.seoul.kr

Department of Cardiology, University of Ulsan College of Medicine, Asan Medical Center, 388-1 Poongnap-dong, Songpa-gu, Seoul 138-736, Korea
}

distal LM bifurcation stenting from a practical point of view.

\section{Outcomes of provisional one-stent and two-stent technique}

The provisional approach is a single-stent strategy that allows the positioning of a second stent, if required (Fig. 1). Similar to non-LM bifurcations, several studies reported that, compared with two-stent techniques, the provisional one-stent approach for distal LM bifurcation was associated with more favorable outcomes, including lower risks of major adverse cardiac events [4-6], death [6], myocardial infarction $[5,6]$, and target vessel revascularization [5-7] (Table 1). In addition, the provisional one-stent approach was found to reduce the risk of stent thrombosis [6, 7]. Based on these results, the provisional one-stent approach has been preferred in the treatment of LM bifurcation stenosis [8], with more than $60 \%$ of patients with LM bifurcation in real-world practice treated using the provisional one-stent technique [5]. However, all previous studies were observational, suggesting the need for randomized controlled studies to properly 

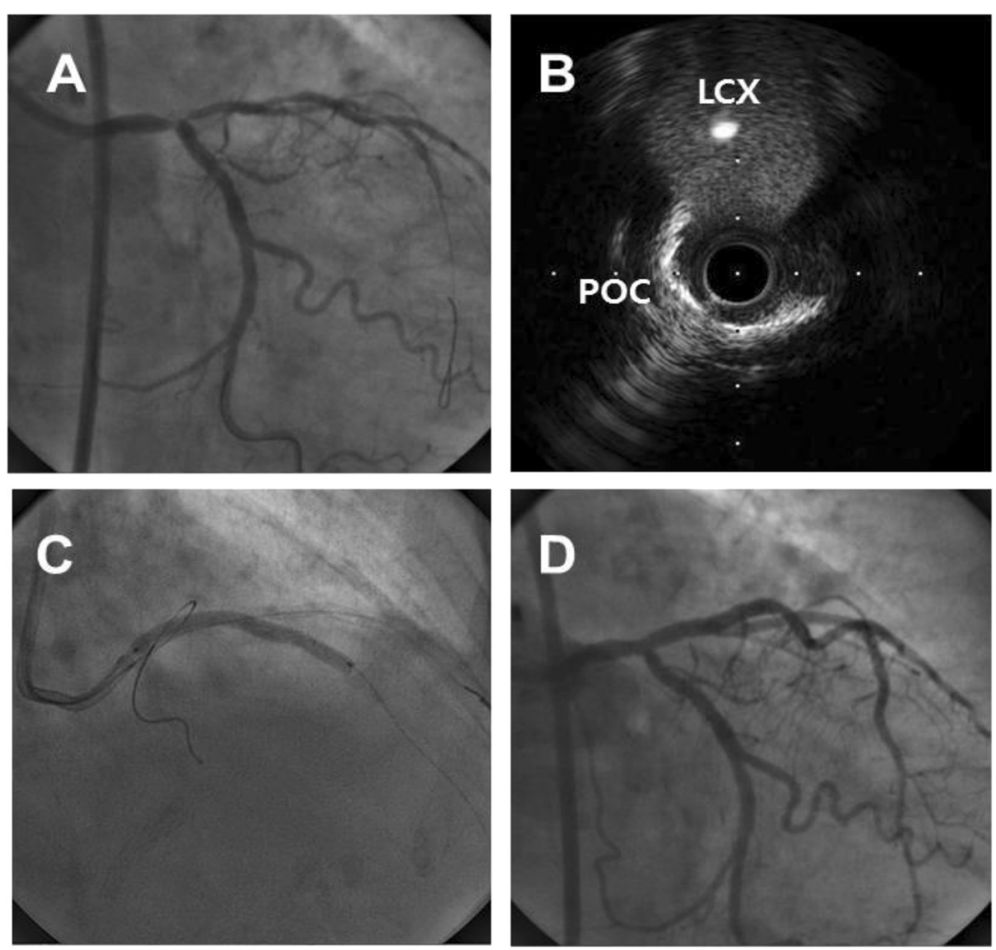

Fig. 1 Provisional approach for distal left main stenosis. Coronary angiography showed a "true" LM bifurcation lesion (Medina 1.1.1) (a) while intravascular ultrasound revealed very minimal disease at the ostium of the left circumflex artery (b). Provisional single stenting was performed (c), with the final angiogram showing an acceptable result without side branch compromise (d)

evaluate the superiority of the provisional approach over double stenting in patients with LM bifurcation disease.

\section{Selecting a left main bifurcation treatment strategy}

Because of the large myocardial volume supplied by the left circumflex artery (LCX) in many patients, the possibility of circulatory collapse after main vessel (MV) stenting should always be considered. Therefore, the presence or absence of significant disease in the ostium of the LCX is regarded as an important factor in choosing a stenting strategy. The provisional one-stent approach is preferred for LM bifurcations with insignificant stenosis at the ostial LCX or a non-dominant left coronary system (Fig. 2). By contrast, the elective two-stent technique is preferred in patients with significant ostial stenosis of the LCX with a dominant left coronary arterial system [9, 10]. Fractional flow reserve (FFR) evaluation for the side branch (SB) has provided valuable information on the relation between physiological and angiographic severity and can be useful to make correct choice of the treatment strategy [11].

Table 1 Outcomes of provisional single stenting versus double stenting

\begin{tabular}{|c|c|c|c|c|c|c|c|c|c|}
\hline \multirow[t]{2}{*}{ Reference } & \multirow[t]{2}{*}{ Year } & \multicolumn{2}{|c|}{ Numbers of patients } & \multirow{2}{*}{$\begin{array}{l}\mathrm{FU} \\
\text { (M) }\end{array}$} & \multicolumn{5}{|c|}{ Adjusted hazard ratio (95\% confidence interval) ${ }^{a}$} \\
\hline & & $\begin{array}{l}\text { Provisional } \\
\text { approach }\end{array}$ & $\begin{array}{l}\text { Double } \\
\text { stenting }\end{array}$ & & MACE & Death or Ml & Death & $\mathrm{Ml}$ & TVR \\
\hline Palmerini [4] & 2008 & 456 & 317 & 24 & $\begin{array}{l}0.48(0.33-0.69) \\
p=0.001\end{array}$ & $\begin{array}{l}0.38(0.17-0.85) \\
p=0.018\end{array}$ & - & - & - \\
\hline Toyofuku [7] & 2009 & 261 & 119 & 36 & - & - & $\begin{array}{l}0.61(0.34-1.08) \\
p=0.09\end{array}$ & - & $\begin{array}{l}0.32(0.18-1.21) \\
p<0.01\end{array}$ \\
\hline Kim [5] & 2011 & 234 & 158 & 36 & $\begin{array}{l}0.89(0.22-0.67) \\
p<0.001\end{array}$ & - & $\begin{array}{l}0.77(0.28-2.13) \\
p=0.62\end{array}$ & $\begin{array}{l}0.38(0.19-0.78) \\
p=0.008\end{array}$ & $\begin{array}{l}0.16(0.05-0.57) \\
p=0.005\end{array}$ \\
\hline Song [6] & 2014 & 509 & 344 & 36 & $\begin{array}{l}0.42(0.28-0.63) \\
p<0.001\end{array}$ & $\begin{array}{l}0.48(0.25-0.93) \\
p=0.03\end{array}$ & $\begin{array}{l}0.30(0.11-0.81) \\
p=0.02\end{array}$ & $\begin{array}{l}0.41(0.18-0.95) \\
p=0.04\end{array}$ & $\begin{array}{l}0.47(0.32-0.69) \\
p<0.01\end{array}$ \\
\hline
\end{tabular}

Abbreviations: FU follow-up, $M$ months, MACE major adverse cardiac events, MI myocardial infarction, TVR target vessel revascularization

${ }^{a}$ Hazard ratios are for patients undergoing the provisional approach, compared with patients undergoing double stenting 

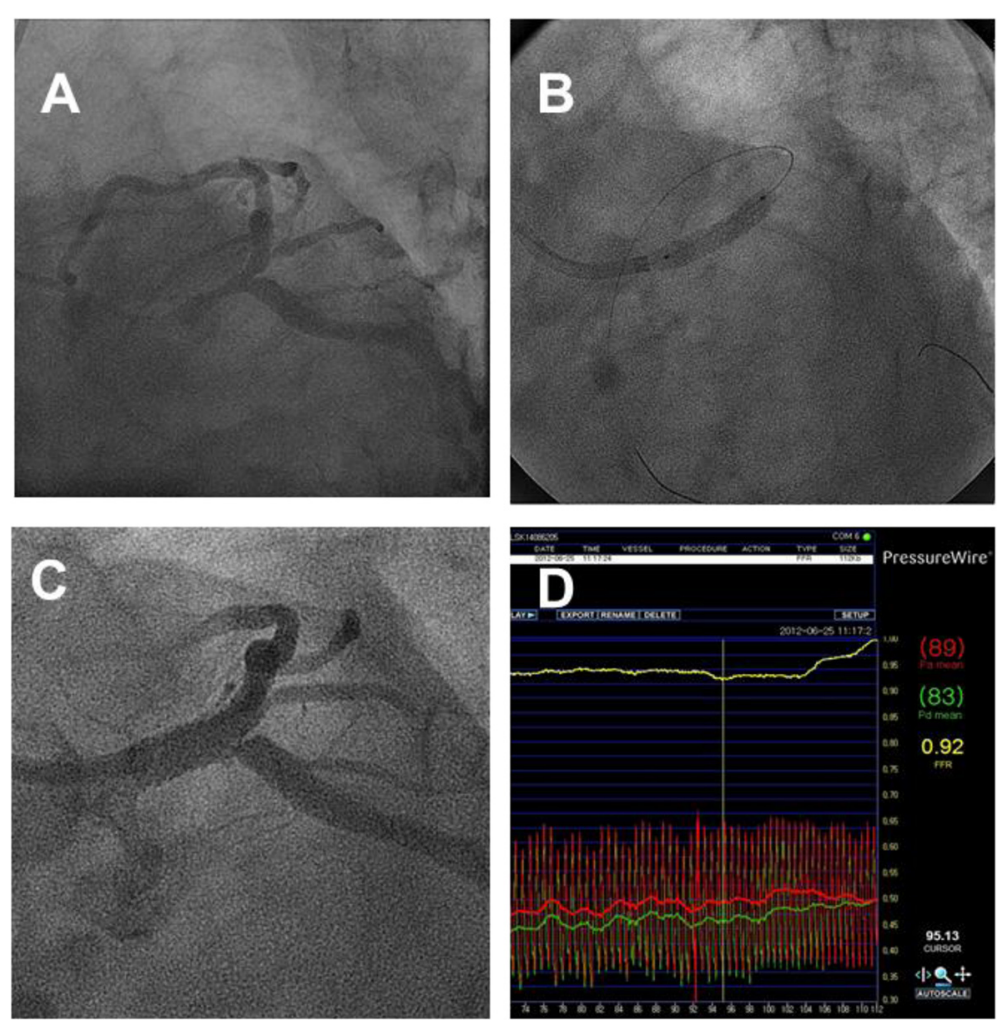

Fig. 2 Fractional flow measurement after main vessel stenting. A patient with a distal LM bifurcation disease (a) underwent provisional one-stent implantation (b). After main vessel stenting, significant stenosis was observed at the ostium of the left circumflex artery (c). However, fractional flow reserve value was 0.92 , indicating functionally insignificant stenosis (d), and suggesting that additional procedures were unnecessary

Table 2 summarizes the selection criteria for stenting strategies based on the anatomic features involving the LM bifurcation.

In general, LM bifurcation disease is mostly diffuse, not focal [12], and angiography is inaccurate in assessing the disease severity of both branch ostia [13]. Thus angiography-guided intervention may lead to SB occlusion for a "true" bifurcation or unnecessary complex intervention that may be preventable. As intravascular ultrasound (IVUS) provides more accurate information on the disease status of the distal LM complex, including the LCX ostium, pre-procedural IVUS evaluation is very helpful in selecting an appropriate and safe stenting strategy. Previous studies reported that the use of IVUS reduced the risk of SB occlusion after MV stenting in coronary bifurcation lesions [9]. Moreover, IVUS-guided PCI for LM disease has been associated with low mortality rates $[14,15]$. In association with the functional concept, IVUS-derived minimal lumen $>3.7 \mathrm{~mm}^{2}$ or plaque burden $<56 \%$ in the LCX ostium can exclude functional SB compromise $($ FFR $<0.80)$ after MV stenting in treating LM bifurcations [16]. However, in

Table 2 Selection criteria for the provisional one-stent approach versus the planned two-stent technique

\begin{tabular}{|c|c|}
\hline Strategy & Anatomical features \\
\hline Favors the Provisional Approach & $\begin{array}{l}\text { - Insignificant stenosis at the ostial LCX with MEDINA classification } 1,1,0 \text { or } 1,0,0 \\
\text { - Small LCX }<2.5 \mathrm{~mm} \text { in diameter } \\
\text { - Diminutive } L C X \text {, right dominant coronary system } \\
\text { - Wide angle between LAD and LCX } \\
\text { - No concomitant disease or only focal disease in LCX }\end{array}$ \\
\hline Favors the Two-Stent Technique & $\begin{array}{l}\text { - Significant stenosis at the ostial LCX with MEDINA classification } 1,1,1 \text { or } 1,0,1 \text { or } 0,1,1 \\
\text { - Large } L C X \geq 2.5 \mathrm{~mm} \text { in diameter } \\
\text { - Diseased left dominant coronary system } \\
\text { - Narrow angle between LAD and LCX } \\
\text { - Concomitant diffuse disease in LCX }\end{array}$ \\
\hline
\end{tabular}


addition to these absolute numerical values reflecting lumen patency, relative plaque distribution [17] and the presence of calcified plaque [18] should also be considered in order to avoid the SB compromise after MV stenting.

\section{Determining SB intervention using the provisional one-stent approach}

Patients who develop ischemic symptoms or signs after MV stenting attributable to SB compromise definitely require further $\mathrm{SB}$ intervention. However, it remains unclear whether further treating asymptomatic angiographic stenosis of an SB ostium after MV stenting provides clinical advantages. Nevertheless, in practice, additional SB interventions are frequently performed, primarily because of concerns regarding the future likelihood of SB deterioration.

Two small pilot studies suggested the benefit of FFRguided decision making for SB intervention after MV stenting in LM bifurcation $[16,19]$. These studies reported a considerable discrepancy between angiographic stenosis and FFR values, in that less than one-third of angiographically isolated LCX ostia were functionally significant (FFR, <0.80). This finding, and results suggesting that a FFR $>0.80$ is a strong predictor of favorable survival and low event rates in patients with coronary artery disease, including intermediate LM disease [20, 21], indicates that incorporating the FFR-guided PCI strategy to treat the isolated LCX may reduce the incidence of additional SB intervention and associated procedurerelated complications. However, long-term clinical trials are needed to validate this FFR-guided SB approach in LM bifurcation stenting.

\section{Elective two-stent techniques}

A planned two-stent approach can be attempted if the operator is concerned about acute complications, including hemodynamic compromise and peri-procedural myocardial infarction following SB loss. Current two-stent techniques commonly used for distal LM bifurcations include crush and its variants, culotte, and simultaneous kissing stent technique. Because few studies have evaluated the comparative outcomes of these two-stent techniques, there are still no clear guidelines in selecting a particular technique relative to the specific anatomy of the LM bifurcation lesion. Thus, selecting a proper stenting technique should depend on each the patient's clinical manifestations, LM bifurcation morphology (e.g. the diameter of the two branches, bifurcation angle, severity of the ostial SB stenosis, extent of the MV disease), and the operator's preference. Also, the operator should make every effort to understand the advantages and disadvantages of the various two-stent techniques.
The crush technique is a modified version of the $\mathrm{T}$ or kissing stent technique, in which the main branch (MB) stent crushes the SB stent against the MB wall. The classic crush technique is performed by retracting the $\mathrm{SB}$ stent $4-5 \mathrm{~mm}$ into the $\mathrm{MB}$ lumen, followed by crushing by the $\mathrm{MB}$ stent. In contrast with the shortcomings of T-stenting, which may leave a small un-stented gap at the SB ostium, the crush technique provides complete lesion coverage for the SB ostium and can be applied to any anatomic variation of true LM bifurcation. By contrast, the formation of three layers of struts covering the $\mathrm{SB}$ ostium just after $\mathrm{MB}$ stenting can make the final kissing balloon inflation (FKI) laborious and may cause unsatisfactory results. Because of these limitations and the complex procedures involved, the mini-crush technique was developed as a variant of the classic crush method. The mini-crush technique involves minimal (usually 1-2 $\mathrm{mm}$ ) retraction of the SB stent into the MB before crushing, thus avoiding a large area with three strut layers and minimizing residual metallic stenosis at the SB ostium [22]. The double-kissing crush technique, another variant of the classic crush method, includes additional kissing balloon inflation between SB crushing and MV stenting and can further enhance stent apposition and facilitate FKI [23]. The culotte technique consists of the sequential implantation of two stents into both branches, with the MV stent implanted through the $\mathrm{SB}$ stent and protruding into the MB lumen. Consequently, the proximal MV is covered by two overlapping stents. This technique is suitable for all angles of bifurcations and provides near-perfect coverage of the SB ostium. However, it may cause intra-procedural acute closure of the MB after SB stenting, which can be catastrophic during interventions for distal LM disease. Since the proximal double stent layers can lead to delayed endothelialization and subsequent stent thrombosis, the stents should be overlapped minimally in the proximal MV segment whenever possible. Finally, the distal MB stent at the ostial left anterior descending artery can be under-expanded because of the positioning through the SB stent strut. The simultaneous kissing stent technique consists of the delivery and implantation of two stents, together with a two-barrel metallic carina, in the LM. The main advantage of this technique is that it guarantees the patency of both branches during the procedure and does not require rewiring for FKI. This technique is preferable in narrow-angle bifurcations, where the LM diameter is much larger than the diameters of the LAD and LCX. Unfortunately, this technique is now rarely used because of several concerns, including difficulty placing the stent proximal to the double barrel, the formation of a new diaphragmatic metal membrane, and difficulty in wiring in case of restenosis [24]. Nevertheless, its technical ease and rapidity make it an appropriate 
option for patients in highly unstable presentations, such as ST-elevation myocardial infarction involving the LM bifurcation. Importantly, one should always beware of the increased risk of bleeding since certain two stent techniques require $7-8 \mathrm{Fr}$ guiding catheter with femoral artery approach.

The particular characteristics of the LM bifurcation should be considered during intervention, in that the absolute difference between the reference vessel diameter of proximal MV and distal MB diameter is relatively large. In this regard, the proximal optimization technique may be of particular importance in LM bifurcation intervention [25]. This technique promotes adequate stent apposition in the LM stem, helps to avoid abluminal rewiring by a second wire, and facilitates rewiring the SB through a distal stent cell which is important for complete scaffolding of the SB ostium. Basically, the choice of stent diameter should be based on the distal MV reference diameter to minimize carina shifting [26, 27]. However, it is also important to select a stent where the platform in that particular nominal diameter accommodates expansion to the reference diameter of the LM coronary artery. The final decision should be made to balance these considerations.

Recently, several dedicated stents for bifurcations have been recently adopted for the treatment of LM disease [28]. These devices offer common advantages over conventional drug-eluting stents (DES) to cover the LM bifurcation segment. The design of these dedicated bifurcation stents and balloons conforms to the natural anatomy of the bifurcation and can facilitate a more effective scaffolding of the SB ostium. Furthermore, these devices provide easier access to the main and side branch which lowers the risk of SB loss during the procedure. Several studies have shown that stenting of LM with these new-dedicated stents is safe and effective both at short and mid-term follow-up [29-32]. Although, conceptually, the advantages offered by these devices may improve clinical outcomes after PCI of LM bifurcations, the success of currently available systems depends on specific anatomic features of bifurcations, and further studies are needed to define their role on LM bifurcations.

\section{Systematic kissing balloon inflation in provisional 1-stent approach}

Systematic FKI after MV stenting is frequently performed in patients undergoing the provisional one-stent approach. Although FKI theoretically allows better strut contact together with the SB opening and is regarded as mandatory in performing any two-stent technique, its role in onestent techniques remains unclear. A recent analysis involving 413 patients who underwent provisional single stenting at Asan Medical Center may provide insight into the use of FKI [33]. Of the 413 patients, 96 received FKI after MV stenting, whereas 318 did not. During a 2 year follow-up period, the rate of the composite of death, myocardial infarction, or target lesion revascularization did not differ significantly between these groups regardless of angiographic SB stenosis (12.5\% vs. $8.5 \%$; adjusted hazard ratio $[\mathrm{HR}], 1.10 ; 95 \%$ confidence interval $[\mathrm{CI}]$, $0.49-2.49, p=0.82$ ). Moreover, although statistically insignificant, there was a trend toward more frequent target vessel revascularization in the FKI group (8.1\% vs. $4.8 \%$; adjusted HR, 1.12; $95 \%$ CI, $0.40-3.11, p=0.83$ ). Another small observational study showed similar results [34]. Therefore, systematic FKI after MV stenting in the provisional one-stent strategy may not provide better long-term clinical outcomes and may be unnecessary.

\section{Importance of intravascular imaging-guided optimization}

Stent under-expansion is the most important cause of DES failure. A minimal stent area (MSA) less than $5.0-5.5 \mathrm{~mm} 2$ was the best predictor on IVUS of firstgeneration DES restenosis or early thrombosis [35, 36]. However, there are no data suggesting the optimal MSA cutoff to predict restenosis and long-term clinical outcomes after DES treatment of LM stenosis-especially since in-stent restenosis can occur within any of the 4 segments: the LCX ostium, the LAD ostium, the polygon of confluence (POC), and the LM above the POC.

The optimal IVUS-MSA criteria for preventing in-stent restenosis were assessed in 403 patients undergoing DES implantation for LM coronary artery disease [37]. The best IVUS-MSA criteria that predicted angiographic restenosis on a segmental basis were $5.0 \mathrm{~mm}^{2}$ for the LCX ostium, $6.3 \mathrm{~mm}^{2}$ for the LAD ostium, $7.2 \mathrm{~mm}^{2}$ for the POC, and $8.2 \mathrm{~mm}^{2}$ for the proximal LM above the POC. Using these criteria, 133 (33.8\%) of the 403 patients had under-expansion of at least one of the pre-specified segments. In addition, under-expansion was more significantly frequent in the two-stent than in the singlestent group ( $54 \%$ vs. $27 \%, p=0.001$ ). In the two-stent group, the LCX ostium was the most common site of under-expansion (37\%), which may explain the greater risk of restenosis when distal LM bifurcation lesions are treated with a two-stent strategy. Overall, angiographic in-stent restenosis was significantly more frequent in lesions with than without under-expansion (24.1\% vs. $5.4 \%, p=0.001)$. Even in the two-stent group, the lesions with complete expansion at all sites showed a restenosis rate of only $6 \%$, similar to that in the single-stent group (6.3\%) or in patients with non-bifurcated LM coronary arteries (4.5\%). Furthermore, a smaller IVUS-MSA predicted angiographic in-stent restenosis 9 months after DES implantation to treat LM disease, and post-stenting under-expansion was an independent predictor of 2 year major adverse cardiac events, especially repeat 
revascularization. This study demonstrates that whichever 2-stent technique is chosen for the LM bifurcation disease, achieving sufficient post-stenting cross-sectional area is important for the favorable clinical outcomes.

Although the clinical impact of IVUS-guided stenting for unprotected LM coronary artery is unclear, as are several cost-benefit issues [38], this adjuvant method has been supported by several recent studies. For example, a subgroup analysis from the MAIN-COMPARE registry, including 201 propensity-score matched pairs, showed that 3 year mortality rates tended to be lower with IVUS than with angiography guidance $(6.3 \%$ vs. $13.6 \%$, logrank $p=0.063$; HR, 0.54; $95 \%$ CI, 0.28-1.03) [14]. In particular, the 3 year mortality rates for the 145 matched pairs of patients undergoing DES implantation was significantly lower with IVUS than with angiography guidance $(4.7 \%$ vs. $16.0 \%$, log-rank $p=0.048$; HR, 0.39; $95 \% \mathrm{CI}, 0.15-1.02)$. Interestingly, mortality rates started to diverge more than 1 year after the procedure. Since IVUS guidance did not reduce the risk of mortality in 47 matched pairs of patients undergoing bare metal stent implantation ( $8.6 \%$ vs. $10.8 \%$, log-rank $p=0.35$; HR, 0.59), this study indicated that IVUS guidance may play a role in reducing very late stent thrombosis and subsequent long-term mortality. A recent IVUSTRONCO-ICP Spanish study also demonstrated the importance of IVUS surveillance during LM coronary artery stenting, with the incidence of the composite of cardiac death, myocardial infarction, and target lesion revascularization, as well as stent thrombosis at 3 years, being lower in the IVUS-guided group [15].

Frequency domain optical coherence tomography (OCT) is another attractive intravascular imaging tool for stent optimization. OCT offers superior resolution and can identify stent failure such as stent malopposition, edge dissections, tissue protrusion, and thrombus more clearly than IVUS [39]. Several pilot studies indeed showed that OCT-guided optimization of LM disease were feasible and safe $[40,41]$. However, since blood must be adequately replaced by iodine contrast through a well-engaged guiding catheter for a clear image by OCT, evaluation of the LM ostium or a relatively large LM is often problematic. Furthermore, there is no standardized OCT criterion for optimizing stent implantation, particularly for the LM bifurcation, which hinders the use of this novel imaging modality to guide LM intervention. Nevertheless, with accumulating clinical data and experience, it is expected that OCT will be a useful adjunctive tool for the treatment of LM disease in near future.

\section{Conclusions}

Figure 3 is a schematic flow chart summarizing clinical strategies for treating distal LM bifurcation disease. Careful selection of candidates for the provisional approach is

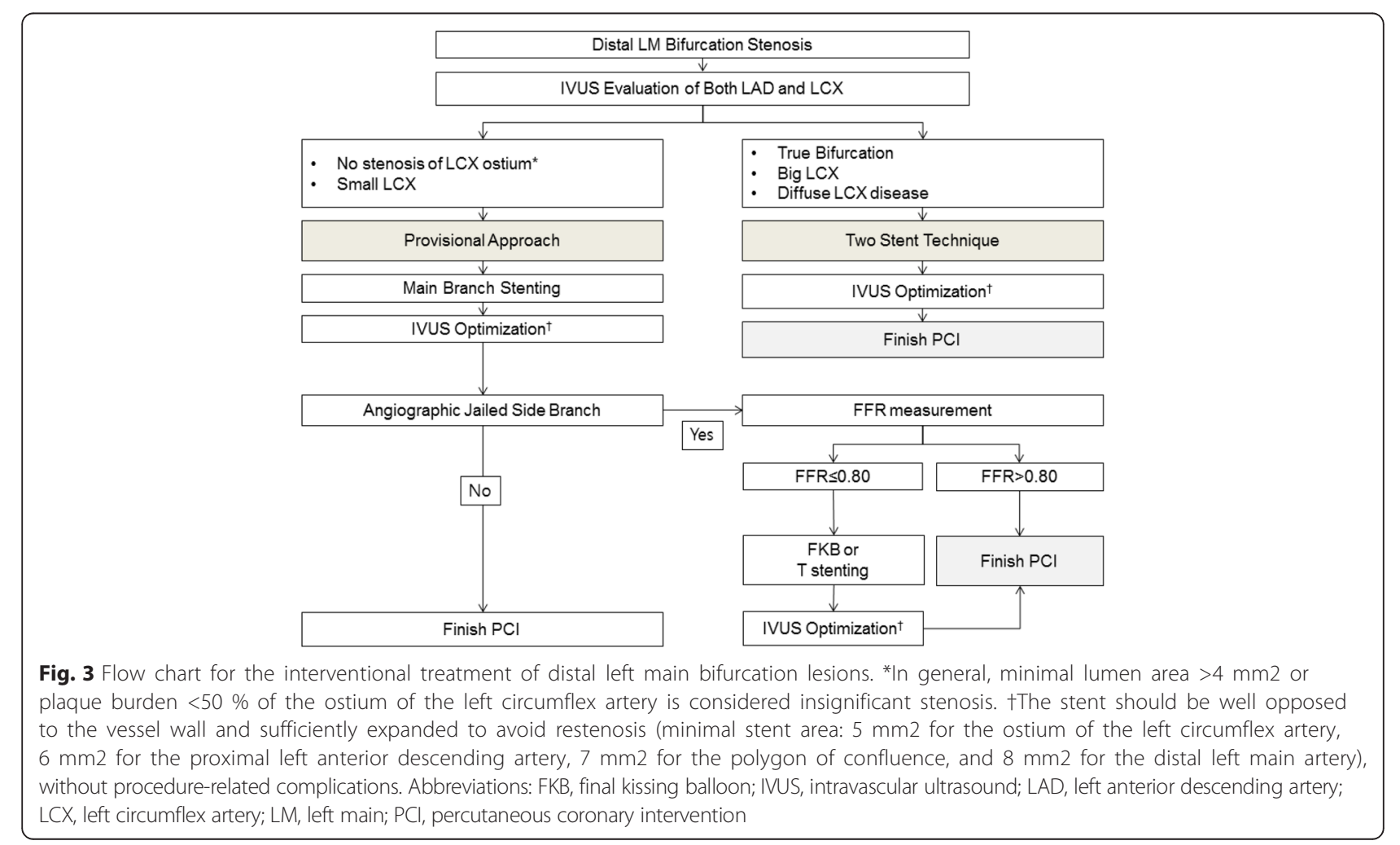


the most important step in avoiding procedure-related complications and ensuring favorable individual outcomes. Incorporating the FFR-guided PCI strategy in treating isolated LCX may further help avoid unnecessary SB interventions. Meticulous evaluation of LM bifurcations using intravascular imaging is crucial in selecting the proper stent strategy and in achieving optimal stent results.

\section{Abbreviations}

Cl: confidence interval; DES: drug-eluting stent; FFR: functional flow reserve; FKl: final kissing balloon inflation; HR: hazard ratio; IVUS: intravascular ultrasound; LCX: left circumflex artery; LM: left main; MB: main branch; MSA: minimal stent area; MV: main vessel; OCT: optical coherence tomography; PCl: percutaneous coronary intervention; POC: polygon of confluence; SB: side branch.

\section{Competing interests}

The authors declare that they have no competing interests.

\section{Authors' contribution}

SJP, PHL, and JMA were responsible for conceiving, structuring, and drafting the manuscript, as well as for revising the manuscript and providing final approval.

\section{Authors' information}

Seung-Jung Park, MD, PhD: Chairman, Heart Institute of Asan Medical Center, University of Ulsan College of Medicine, Seoul, Korea.

\section{Acknowledgements}

None.

Received: 4 February 2016 Accepted: 12 February 2016

Published online: 19 February 2016

\section{References}

1. Windecker S, Kolh P, Alfonso F, Collet JP, Cremer J, Falk V, et al. 2014 ESC/EACTS Guidelines on myocardial revascularization: The Task Force on Myocardial Revascularization of the European Society of Cardiology (ESC) and the European Association for Cardio-Thoracic Surgery (EACTS) Developed with the special contribution of the European Association of Percutaneous Cardiovascular Interventions (EAPCI). Eurolntervention. 2014. doi:10.4244/EIJY14M09_01.

2. Naganuma T, Chieffo A, Meliga E, Capodanno D, Park SJ, Onuma Y, et al. Longterm clinical outcomes after percutaneous coronary intervention for ostial/ mid-shaft lesions versus distal bifurcation lesions in unprotected left main coronary artery: the DELTA Registry (drug-eluting stent for left main coronary artery disease): a multicenter registry evaluating percutaneous coronary intervention versus coronary artery bypass grafting for left main treatment. JACC Cardiovasc Interv. 2013;6(12):1242-9. doi:10.1016/j.jcin.2013.08.005.

3. Kim WJ, Kim YH, Park DW, Yun SC, Lee JY, Kang SJ, et al. Comparison of single- versus two-stent techniques in treatment of unprotected left main coronary bifurcation disease. Catheter Cardiovasc Interv. 2011;77(6):775-82 doi:10.1002/ccd.22915

4. Palmerini T, Marzocchi A, Tamburino C, Sheiban I, Margheri M, Vecchi $\mathrm{G}$, et al. Impact of bifurcation technique on 2-year clinical outcomes in 773 patients with distal unprotected left main coronary artery stenosis treated with drug-eluting stents. Circ Cardiovasc Interv. 2008:1(3):185-92 doi:10.1161/circinterventions.108.800631.

5. Kim WJ, Kim YH, Park DW, Yun SC, Lee JY, Kang SJ, et al. Comparison of single- versus two-stent techniques in treatment of unprotected left main coronary bifurcation disease. Catheter Cardiovasc Interv. 2011;77(6):775-82. doi:10.1002/ccd.22915.

6. Song YB, Hahn JY, Yang JH, Choi SH, Choi JH, Lee SH, et al. Differential prognostic impact of treatment strategy among patients with left main versus non-left main bifurcation lesions undergoing percutaneous coronary intervention: results from the COBIS (Coronary Bifurcation Stenting) Registry II. JACC Cardiovasc Interv. 2014;7(3):255-63. doi:10.1016/j.jcin.2013.11.009.

7. Toyofuku M, Kimura T, Morimoto T, Hayashi Y, Ueda H, Kawai K, et al, Threeyear outcomes after sirolimus-eluting stent implantation for unprotected left main coronary artery disease: insights from the j-Cypher registry. Circulation. 2009:120(19):1866-74. doi:10.1161/CIRCULATIONAHA.109.873349.

8. Lassen JF, Holm NR, Stankovic G, Lefevre T, Chieffo A, Hildick-Smith D, et al. Percutaneous coronary intervention for coronary bifurcation disease: consensus from the first 10 years of the European Bifurcation Club meetings. Eurolntervention. 2014;10(5):545-60. doi:10.4244/EIJV1015A97.

9. Hahn J-Y, Chun WJ, Kim J-H, Song YB, Oh JH, Koo B-K, et al. Predictors and Outcomes of Side Branch Occlusion After Main Vessel Stenting in Coronary Bifurcation Lesions: Results From the COBIS II Registry (COronary Blfurcation Stenting). J Am Coll Cardiol. 2013;62(18):1654-9. doi:10.1016/j.jacc.2013.07.041.

10. Kim YH $\sqcup$, Roh JH, Ahn JM, Yoon SH, Park DW, Lee JY, Yun SC, Kang SJ, Lee SW, Lee CW, Seung KB, Shin WY, Lee NH, Lee BK, Lee SG, Nam CW, Yoon J, Yang JY, Hyon MS, Lee K, Jang JS, Kim HS, Park SW, Park SJ. Optimal Strategy for Bifurcation Lesions: CROSS and PERFECT Trials. J Am Coll Cardiol. 2014;63(12_S2):S2.

11. Koo BK, Waseda K, Kang HJ, Kim HS, Nam CW, Hur SH, et al. Anatomic and functional evaluation of bifurcation lesions undergoing percutaneous coronary intervention. Circ Cardiovasc Interv. 2010;3(2):113-9. doi:10.1161/CIRCINTERVENTIONS.109.887406.

12. Oviedo C, Maehara A, Mintz GS, Araki H, Choi SY, Tsujita K, et al. Intravascular ultrasound classification of plaque distribution in left main coronary artery bifurcations: where is the plaque really located? Circ Cardiovasc Interv. 2010:3(2):105-12. doi:10.1161/CIRCINTERVENTIONS.109.906016.

13. Kang SJ, Mintz GS, Oh JH, Park DW, Lee SW, Kim YH, et al. Intravascular ultrasound assessment of distal left main bifurcation disease: the importance of the polygon of confluence of the left main, left anterior descending, and left circumflex arteries. Catheter Cardiovasc Interv. 2013;82(5):737-45. doi:10.1002/ccd.23263.

14. Park SJ, Kim YH, Park DW, Lee SW, Kim WJ, Suh J, et al. Impact of intravascular ultrasound guidance on long-term mortality in stenting for unprotected left main coronary artery stenosis. Circ Cardiovasc Interv. 2009;2(3):167-77. doi:10.1161/CIRCINTERVENTIONS.108.799494.

15. de la Torre Hernandez JM, Baz Alonso JA, Gomez Hospital JA, Alfonso Manterola F, Garcia Camarero T. Gimeno de Carlos F et al. Clinical impact of intravascular ultrasound guidance in drug-eluting stent implantation for unprotected left main coronary disease: pooled analysis at the patient-level of 4 registries. JACC Cardiovasc Interv. 2014;7(3):244-54. doi:10.1016/j.jcin.2013.09.014.

16. Kang SJ, Ahn JM, Kim WJ, Lee JY, Park DW, Lee SW, et al. Functional and morphological assessment of side branch after left main coronary artery bifurcation stenting with cross-over technique. Catheter Cardiovasc Interv. 2014;83(4):545-52. doi:10.1002/ccd.25057.

17. Yoshitaka Goto Y, Kawasaki T, Koga N, Tanaka H, Koga H, Orita Y, et al. Plaque distribution patterns in left main trunk bifurcations: prediction of branch vessel compromise by multidetector row computed topography after percutaneous coronary intervention. Eurolntervention. 2012:8(6):708-16. doi:10.4244/eijv8i6a110

18. Sato K, Naganuma T, Costopoulos C, Takebayashi H, Goto K, Miyazaki T, et al. Calcification analysis by intravascular ultrasound to define a predictor of left circumflex narrowing after cross-over stenting for unprotected left main bifurcation lesions. Cardiovasc Revasc Med. 2014;15(2):80-5. doi:10.1016/j.carrev.2014.01.014

19. Nam CW, Hur SH, Koo BK, Doh JH, Cho YK, Park HS, et al. Fractional flow reserve versus angiography in left circumflex ostial intervention after left main crossover stenting. Korean Circ J. 2011;41(6):304-7. doi:10.4070/kcj.2011.41.6.304.

20. Hamilos M, Muller O, Cuisset T, Ntalianis A, Chlouverakis G, Sarno G, et al. Longterm clinical outcome after fractional flow reserve-guided treatment in patients with angiographically equivocal left main coronary artery stenosis. Circulation. 2009:120(15):1505-12. doi:10.1161/CIRCULATIONAHA.109.850073.

21. Courtis J, Rodes-Cabau J, Larose E, Potvin JM, Dery JP, Larochelliere RD, et al. Usefulness of coronary fractional flow reserve measurements in guiding clinical decisions in intermediate or equivocal left main coronary stenoses. Am J Cardiol. 2009;103(7):943-9. doi:10.1016/j.amjcard.2008.11.054.

22. Ormiston JA, Webster MWI, Webber B, Stewart JT, Ruygrok PN, Hatrick RI. The "Crush" Technique for Coronary Artery Bifurcation Stenting: Insights From Micro-Computed Tomographic Imaging of Bench Deployments. JACC Cardiovasc Interv. 2008;1(4):351-7.

23. Chen S-L, Xu B, Han Y-L, Sheiban I, Zhang J-J, Ye F, et al. Comparison of Double Kissing Crush Versus Culotte Stenting for Unprotected Distal Left Main Bifurcation Lesions: Results From a Multicenter, Randomized, 
Prospective DKCRUSH-III Study. J Am Coll Cardiol. 2013;61 (14):1482-8. doi: 10.1016/j.jacc.2013.01.023.

24. Kim YH, Park DW, Suh IW, Jang JS, Hwang ES, Jeong YH, et al. Long-term outcome of simultaneous kissing stenting technique with sirolimus-eluting stent for large bifurcation coronary lesions. Catheter Cardiovasc Interv. 2007;70(6):840-6.

25. Hildick-Smith D, Lassen JF, Albiero R, Lefevre T, Darremont O, Pan M, et al. Consensus from the 5th European Bifurcation Club meeting. Eurolntervention. 2010;6(1):34-8. doi:10.4244/.

26. Kang SJ, Mintz GS, Kim WJ, Lee JY, Oh JH, Park DW, et al. Changes in left main bifurcation geometry after a single-stent crossover technique: an intravascular ultrasound study using direct imaging of both the left anterior descending and the left circumflex coronary arteries before and after intervention. Circ Cardiovasc Interv. 2011;4(4):355-61. doi:10.1161/CIRCINTERVENTIONS.110.961045.

27. Kang SJ, Kim WJ, Lee JY, Park DW, Lee SW, Kim YH, et al. Hemodynamic impact of changes in bifurcation geometry after single-stent cross-over technique assessed by intravascular ultrasound and fractional flow reserve. Catheter Cardiovasc Interv. 2013;82(7):1075-82. doi:10.1002/ccd.24956.

28. Grundeken MJ, Magro M, Gil R, Briguori C, Sardella G, Berland J, et al. Dedicated stents for distal left main stenting. Eurolntervention. 2015;11(Suppl V):V129-V34. doi:10.4244/EIJV11SVA29.

29. Hasegawa T, Ako J, Koo BK, Miyazawa A, Sakurai R, Chang H, et al. Analysis of left main coronary artery bifurcation lesions treated with biolimus-eluting DEVAX AXXESS plus nitinol self-expanding stent: intravascular ultrasound results of the AXXENT trial. Catheter Cardiovasc Interv. 2009;73(1):34-41. doi:10.1002/ccd.21765.

30. Lucisano L, Calcagno S, Pennacchi M, Stio RE, Mancone M, Sardella G. Results of the self-expandable BA9 stent for treatment of large angle coronary bifurcation. Minerva Cardioangiol. 2014;62(1):19-27.

31. Magro M, Girasis C, Bartorelli AL. Tarantini G, Russo F, Trabattoni D et al. Acute procedural and six-month clinical outcome in patients treated with a dedicated bifurcation stent for left main stem disease: the TRYTON LM multicentre registry. Eurolntervention. 2013;8(11):1259-69. doi:10.4244/EIJV8111A194.

32. Bil J, Gil RJ, Vassilev D, Rzezak J, Kulawik T, Pawlowski T. Dedicated bifurcation paclitaxel-eluting stent BiOSS Expert( $R$ ) in the treatment of distal left main stem stenosis. J Interv Cardiol. 2014;27(3):242-51. doi:10.1111/joic.12119.

33. Park S-J, Ahn J-M, Park H-S, Cheon SS, Kim MS, Roh JH, et al. TCT-234 is final kissing ballooning mandatory in the treatment of distal left main disease treated by simple cross over stenting? J Am Coll Cardiol. 2014;64(11_S):11_S. doi:10.1016/.jacc.2014.07.276.

34. Rha S-W, Elnagar A, Choi SY, Choi BG, Im Sl, Kim S, et al. AS-174 Role of Final Kissing Balloon for Unprotected Distal Left Main Bifurcation Intervention with Single Stent Strategy. Am J Cardiol.109(7):S86-S7. doi:10.1016/.jamjcard.2012.01.199.

35. Hong MK, Mintz GS, Lee CW, Park DW, Choi BR, Park KH, et al. Intravascular ultrasound predictors of angiographic restenosis after sirolimus-eluting stent implantation. Eur Heart J. 2006;27(11):1305-10. doi:10.1093/eurheartj/ehi882.

36. Sonoda S, Morino Y, Ako J, Terashima M, Hassan AH, Bonneau HN, et al. Impact of final stent dimensions on long-term results following sirolimuseluting stent implantation: serial intravascular ultrasound analysis from the sirius trial. J Am Coll Cardiol. 2004;43(11):1959-63. doi:10.1016/j.jacc.2004.01.044.

37. Kang SJ, Ahn JM, Song H, Kim WJ, Lee JY, Park DW, et al, Comprehensive intravascular ultrasound assessment of stent area and its impact on restenosis and adverse cardiac events in 403 patients with unprotected left main disease. Circ Cardiovasc Interv. 2011;4(6):562-9. doi:10.1161/CIRCINTERVENTIONS.111.964643.

38. Agostoni P, Valgimigli M, Van Mieghem CA, Rodriguez-Granillo GA, Aoki J, Ong AT, et al. Comparison of early outcome of percutaneous coronary intervention for unprotected left main coronary artery disease in the drug-eluting stent era with versus without intravascular ultrasonic guidance. Am J Cardiol. 2005;95(5):644-7. doi:10.1016/.amjcard.2004.10.042.

39. Waksman R, Kitabata H, Prati F, Albertucci M, Mintz GS. Intravascular ultrasound versus optical coherence tomography guidance. J Am Coll Cardiol. 2013;62(17 Suppl):S32-40. doi:10.1016/j.jacc.2013.08.709.

40. Burzotta F, Dato I, Trani C, Pirozzolo G, De Maria GL, Porto I, et al. Frequency domain optical coherence tomography to assess non-ostial left main coronary artery. Eurolntervention. 2015;10(9):e1-8. doi:10.4244/EIJV1019A179.

41. Fujino Y, Bezerra HG, Attizzani GF, Wang W, Yamamoto H, Chamie D, et al. Frequency-domain optical coherence tomography assessment of unprotected left main coronary artery disease-a comparison with intravascular ultrasound. Catheter Cardiovasc Interv. 2013;82(3):E173-83. doi:10.1002/ccd.24843.

\section{Submit your next manuscript to BioMed Central and we will help you at every step:}

- We accept pre-submission inquiries

- Our selector tool helps you to find the most relevant journal

- We provide round the clock customer support

- Convenient online submission

- Thorough peer review

- Inclusion in PubMed and all major indexing services

- Maximum visibility for your research

Submit your manuscript at www.biomedcentral.com/submit
() BioMed Central 